\title{
Competency of School Teachers Regarding Learning Disabilities
}

\author{
Ms. Anjana Williams ${ }^{1}$, Mrs. Grace Singh ${ }^{2}$, Mrs.Priya J.P.Narayan ${ }^{3}$ \\ 1,2, (Mental Health Department, Himalayan College of Nursing, Dehradun, Uttarakhand, India) \\ ${ }^{3}$ (Medical Surgical Nursing, Himalayan College of Nursing, Dehradun, Uttarakhand, India)
}

\begin{abstract}
Quasi experimental Study was conducted to evaluate the effectiveness of a Learning Package on competency of Primary School Teachers regarding Learning Disabilities among children. The study was conducted in a Primary School of Bhainyawala, Dehradun. Total 38 teachers were selected who met the inclusion criteria by non-probability, convenience sampling technique. Pretest was taken by structured knowledge questionnaire, attitude scale and knowledge of skill checklist followed by Learning Package and post- test was taken after 7 days which showed that mean post -test knowledge score (13.7 \pm 3.2$)$ was higher

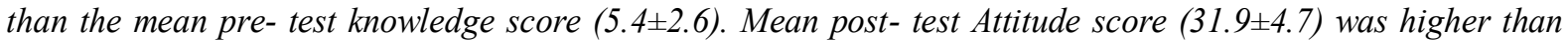

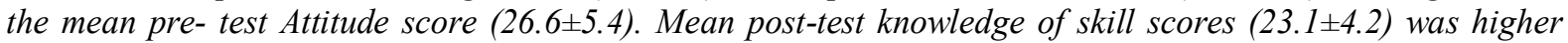
than the mean pre-test knowledge of skill scores (17.2 66.6). After post- test the knowledge, attitude and skills of primary school teachers had increased significantly. Hence it is proved that the Learning Package improves the competency of primary school teachers regarding Learning Disabilities.
\end{abstract}

Keywords: Competency, Learning Disabilities, Learning package, Primary school teachers.

\section{INTRODUCTION}

Learning is any relative permanent change in behavior that occurs as a result of practice or experience.Theterm "Learning Disorder", formally referred to as 'academic skills,' and was introduced by $4^{\text {th }}$ edition of DSM-IV. It includes Reading disorder (F81.0/315.02), Disorder of written expression (F81.1/315.2), Mathematics disorder (F81.2-3/315.1) and Learning disorder not otherwise specified The term "Learning Disability" (LD) was first apparently used and defined in 1963 by Psychologist Dr. Samuel Kirk .This term was referred to a discrepancy between a child's apparent capacities to learn as his or her level of achievement as compared to others National Joint Committee on Learning Disabilities defines the term Learning Disability (LD)as a heterogeneous group of disorders manifested by significant difficulties in the acquisition and use of listening, speaking (dysphasia), reading (dyslexia), writing (dysgraphia), reasoning or mathematical (dyscalculia) and motor skill (dyspraxia) abilities.School is the "workplace" where children and adolescents performtask, learn and discover themselves as an individuals.Successful performance is essential for psychological growth and development of self-esteem and confidence in the child. On the other side, a child with learning disabilities struggles with school-work, failing grades and low self -esteem.

Teachers' abilities to assess the LD are an essential component. Appropriate assessments enable teachers to recognize the early signs that a child may be at risk for LD, and the assessments permit teachers to target instructions to meet individual student needs. Scientists claimed that with the use of effective training programs, the brain can be rewired and children can learn to read and can do much better in their lives.

\subsection{Need for the study}

In 1973, it was estimated that worldwide 1-3\% of children had LD which increased up to $4-5 \%$ and by in 1994.Majority (60\%) of the children had Reading Disability. There is strong evidence that individuals with LD experience more social, emotional, and motivational difficulties than those without LD.

Village level surveys in India reveals that $4-10 \%$ of population constitute Persons with Disability and around 13-14 \% of all school children suffer from learning disorders which goes unnoticed. In India, prevalence estimates of LD range from $9-39 \%$ and the incidence of dyslexia in primary school children has been reported to be $2-18 \%$, dysgraphia $14 \%$, and dyscalculia $5.5 \%$.

Unfortunately, most of the schools do not understand the intensity of the, problem and it remains unfocused; as a result, these children are identified as failures in the learning process. Hence, the researcher was motivated and felt the need to study on LD and strongly believes that challenges can be overcome with the help of support and timely guidance. What matter is someone has to take charge. It is relevant to educate the primary school teachers on early identification of LD which will help the student in various aspects.

\subsection{Statement of Problem}

A Quasi experimental study to evaluate the effectiveness of a Learning Package on competency of Primary School Teachers regarding Learning Disabilities (LD) of children, in selected school of Dehradun, Uttarakhand, India, 2012 


\subsection{Objectives}

1. To evaluate the effectiveness of a Learning package on competency of Primary School Teachers regarding Learning Disabilities of children in terms of their competency scores.

2. To find association between the pretest levels of knowledge, attitude, practice scores of primary school teachers regarding Learning Disabilities with their selected baseline profile.

\subsection{Hypothesis}

$\mathbf{H}_{1}$-The mean post-test Competency (Knowledge, Attitude and Knowledge of Skill) scores of Primary School Teachers regarding Learning Disabilities would be significantly higher than that of their mean pre-test Competency scores.

$\mathbf{H}_{2}$ - There would be significant association between pretest Competency (Knowledge, Attitude and Knowledge of Skills) score and selected socio-demographic data of Primary School teachers regarding Learning Disabilities.

\subsection{Conceptual framework}

The investigator adopted modified Wiedenbach 'A Helping Art of Clinical Nursing' 1964 conceptual model for the present study.

\section{MATERIAL AND METHODS}

A Quasi-experimental with one group pretest - post-test research design was used in present study. The study was conducted in Doon International School, Bhainyawala, Dehradun, Uttarakhand. The samples of 38 primary school teachers were selected through convenient sampling technique. Tools designed by the researcher used for the study were structured knowledge questionnaire, attitude scale and knowledge of skill checklist and sociodemographic variables like age, educational status, teaching experience, previous knowledge about the topic, and source of information about the LD. Content validity of tool was ensured by experts in the field of Psychiatry, Clinical Psychology, Speech Therapy, and Mental Health Nursing. Pilot study was conducted on 5 Primary School Teachers of Bhainyawala, Dehradun, Uttarakhand. Reliability of tool was established by Karl Pearson's Correlation coefficient. Reliability of the tool was established as $r=0.85$. The reliability of attitude and knowledge of skill checklist was done through test retest method and it was $r=0.9$.

\section{RESULTS AND FINDINGS}

\subsection{Socio-demographic variables of primary school teachers.}

According to sample characteristics of Primary school teachers shown in table no1, majority of the teachers falls in the age group of 20 to 36 years $(61 \%)$. Twenty four $(63.15 \%)$ of the teachers were post graduate and 33 (86.84) teachers had previous working experience between $0-10$ years. Twenty three $(60.52 \%)$ teachers had no previous knowledge regarding LD. Eight teachers (21.05\%) got the information about the learning Disabilities from media source.

Table no. : 1 Socio-demographic data of the Primary School Teachers

\begin{tabular}{|c|c|c|}
\hline Sample Characteristics & Frequency (F) & Percentage (\%) \\
\hline \multicolumn{3}{|l|}{ Age In Years } \\
\hline $20-35$ & 28 & 74 \\
\hline $36-50$ & 10 & 26 \\
\hline \multicolumn{3}{|l|}{ Educational Status } \\
\hline Graduate & 14 & 37 \\
\hline Postgraduate & 24 & 63 \\
\hline \multicolumn{3}{|l|}{ Teaching Experience } \\
\hline $0-10$ & 33 & 87 \\
\hline $11-20$ & 5 & 13 \\
\hline \multicolumn{3}{|l|}{ Previous Knowledge } \\
\hline Yes & 15 & 40 \\
\hline No & 23 & 60 \\
\hline \multicolumn{3}{|l|}{ Source Of Information } \\
\hline Media & 8 & 21 \\
\hline Workshop & 6 & 16 \\
\hline Course & 1 & 3 \\
\hline No & 23 & 60 \\
\hline
\end{tabular}

3.2 Effectiveness of learning package on competency Scores of study subjects. Table no. 2:Effectiveness of learning package on competency Scores of study subjects 


\begin{tabular}{|c|c|c|c|c|c|c|}
\hline & $\begin{array}{c}\text { Pre-test } \\
\text { Range score }\end{array}$ & $\begin{array}{c}\text { Pre-test } \\
\text { Mean } \pm \text { SD }\end{array}$ & $\begin{array}{c}\text { Post-test } \\
\text { Range score }\end{array}$ & $\begin{array}{c}\text { Post-test } \\
\text { Mean } \pm \text { SD }\end{array}$ & $\begin{array}{c}\text { Mean } \\
\text { difference }\end{array}$ & $\begin{array}{c}\mathbf{t} ' \\
\text { value }\end{array}$ \\
\hline $\begin{array}{l}\text { Knowledge } \\
\text { Scores }\end{array}$ & $1-15$ & $5.4 \pm 2.6$ & $5-20$ & $13.7 \pm 3.2$ & 8.3 & $12.8 * *$ \\
\hline $\begin{array}{l}\text { Attitude } \\
\text { Scores }\end{array}$ & $15-40$ & $26.6 \pm 5.4$ & $22-40$ & $31.9 \pm 4.7$ & 5.3 & $4.6 *$ \\
\hline Practice Scores & $0-29$ & $17.2 \pm 6.6$ & $15-29$ & $23.1 \pm 4.2$ & 5.9 & $4.5 *$ \\
\hline
\end{tabular}

Data presented in Table no2 shows that the mean of post -test knowledge score (13.7) was higher than the mean of pre-test knowledge score (5.4). Hence the scores predict that difference of mean observed was of true difference and the 'Learning package' was effective to upgrade knowledge of primary school teachers. The mean post-test Attitude score (31.9) was higher than the mean pre-test Attitude score (26.6). Hence the scores predict that the 'Learning package' was effective to change the neutral attitude into positive.

Findings in Table no 2 shows that the mean post-test of knowledge of skill scores (23.1) were higher than the mean of pretest knowledge of skill scores (17.2). Hence the scores predict that 'Learning Package' was effective to improve the practice of primary school teachers. Thus it could be inferred that 'Learning Package' was found to be effective and it improved the knowledge and the skill based knowledge of teachers. As the attitude of teachers were already at positive and neutral side but after the intervention scores shifted to positive side more.

\subsection{Association between Pretest competency scores and Socio-demographic data}

In the present study there was no association was found between socio-demographic data and pre-test knowledge, attitude and practice scores, except the previous knowledge of respondents with their knowledge score. This proves that those who had previous exposure on the topic have more knowledge gain as compare to the one who had no previous exposure about LD.

Nursing Practice:

\section{NURSING IMPLICATIONS}

Learning Package developed and conducted by nursing personnel in school areas helps in enhancing the knowledge about learning disabilities.

\section{Nursing Education:}

Nursing teachers should emphasize the importance of awareness of learning disabilities and how to assess them in student nurses and patients.

\section{Nursing Administration:}

The nurse, as an administrator, should plan and organize workshops and other related programmes for the nursing personnel and motivate them in conducting instructional teaching programs regarding learning disabilities in schools and selected community settings, which will be beneficial for the community.

\section{Nursing Research:}

Research provides nurses the credibility to influence decision making, policy and protocol formulation regarding interventional strategies to meet the specific need for educating teachers regarding learning disabilities and how to improve learning abilities. Findings of the present study suggest that nurses working in the community must encourage the school teacher about the importance of learning, its types and about the learning disabilities of the students and how to improve them. An explorative study can also be conducted on knowledge and attitude of parents regarding learning disabilities.

\section{CONCLUSION}

Today, teachers are more aware and have positive attitude towards children with learning disabilities, but have less knowledge about the sign and symptoms and management of children with LD. The priority of the teachers is to be focused on helping all children learn to reach the highest levels of their potentials. Primary school teachers were deficient in knowledge and skill in spite of working with children with LD. Learning Package is an effective method to increase the competency of Primary School Teachers regarding LD by saying that cognitive change can be brought about by teaching programme.

Another aspect of improvement in knowledge is improvement in attitude of teachers regarding the LD. Although the study sample was small, which limits the generalization of study, it can be concluded that knowledge, attitude and skills can be improved through learning packages. Future similar studies may be replicated on a larger sample, to determine the knowledge and attitude of parents of children with LD. It can also be done to determine the knowledge, attitude of teachers of higher classes regarding LD. 


\section{ACKNOWLEDGEMENT}

We would like to show our greatest appreciation for Dr. Kathleen Mckeehan, Nursing Consultant,Himalayan College of Nursing for her tremendous support and help. We would like to gratefully acknowledge the enthusiastic supervision of Dr. Sanchita Pugazhendi, Principal of Himalayan college of Nursing, Dehradun without the encouragement and guidance it would not have been possible to publish this article. We would be failing if we don't appreciate the efforts taken by Research committee of HIHT, Dehradun, Uttarakhand

\section{REFERENCES}

[1]. Psychology Wiki. Introduction to learning disability[homepage on the internet]. psychology.wikia.com;[cited on2012 May 14] Available from: http://psychology.wikia.com/wiki/Introduction_to_learning_disability

[2]. Knowledge and practice standards articlebase.com [cited on 2011 march 21] available from www.interdys.org/ewebeditpro5/.../Knowledge and Practice Standards.pdf

[3]. KlassenRM,Lynch SL. Self-Efficacy From the Perspective of Adolescents With LD and Their Specialist Teachers' Learn Disabil. 2007 November/December; 40(6): 494-507.

[4]. Web health center. Disability in India/Get Help[homepage on the internet] Web health center;[updated 2011 April 11 ; cited 2011 August Available from: www.webhealthcenter.com/diseaseconditions/cerebral-palsy-india.aspx

[5]. Padmavati D, Lalitha K. Effectiveness of Structured Teaching Programme for teachers towards learning disabilities. Nightingale Nursing Times. 2009 Jul;05(04):14-7.

[6]. Learning disability article[Internet document].cited in august 2011 available from http://www.articlesbase.com/educationarticles/learning-disability-in-india-1126528.html 